\title{
Inconvenient Truths and Comforting Fictions: Cognitive Dissonance in Philosophical Interpretations of Woody Allen's Crimes and Misdemeanors
}

\author{
Péter Csató
}

The study which follows is a counterpart to an earlier paper of mine on Woody Allen's Crimes and Misdemeanors (1989) ${ }^{2}$, in which I perform a critical reading of the film in the context of pragmatist philosophy, especially with regard to William James's and Richard Rorty's concepts of truth and morality. While the present analysis also revolves around the same filmic narrative, and addresses issues related to ethics and morality, overlaps with the previous text are minimal. This paper is situated in a different conceptual and philosophical framework, and its intention is twofold: on the one hand, it is intended to be a metacritical study, insofar as its primary purpose is to analyze critical commentaries on the film, which aim to sublimate Allen's skeptical and highly critical take on conventional approaches to ethics and morality; on the other hand, it wishes to formulate a philosophical argument in its own right. My contention is that Allen's skepticism (in Crimes and Misdemeanors as well as in some other major films in the same period) is not merely an upshot of his artistic extravagance, but an integral part of a conceptual outlook, whereby his films in question take a consistent philosophical stance, rather than just convey an artistic vision. I will maintain that the critical analyses which aim to offer a corrective to what they deem a bleak artistic vision can be interpreted as reducing the cognitive dissonance which is generated by the discrepancy between the critics' own moral and/or philosophical convictions and the uncompromising demystifications that Allen performs in his films.

\section{Demystification, anxiety, and cognitive dissonance}

In the middle-period of his filmmaking career, Woody Allen's proprietary brand of black humor tends to manifest itself in the form of caricatural representations of bleak and pessimistic dispositions, where much of the comedy stems from the cosmic irony of characters from mundane backgrounds and amidst quotidian predicaments confronting some of the most unsettling questions of human

2 "Pragmatism Goes to the Movies: Pragmatic Conceptions of Truth in Woody Allen's Crimes and Misdemeanors". Hungarian Journal of English and American Studies (HJEAS) 20.12014 11-28. 
existence and the universe at large. Sandy Bates, the main character in Stardust Memories (1980), is a case in point: after he gets assassinated by a disillusioned fan in an imaginary sequence, his psychoanalyst (Leonardo Cimino) shares the following reminiscence about his former patient: "He was a complicated patient. He saw reality too clearly_faulty denial mechanism failed to block out the terrible truths of existence. In the end, his inability to push away the awful facts of 'beingin-the-world' rendered his life meaningless, or as one great Hollywood producer said: 'Too much reality is not what the people want."' In Annie Hall (1977) the childhood persona of the Allen-character, Alvy Singer (Jonathan Munk), decides to stop doing homework, because he has read that "the universe is expanding, and if it's expanding, then someday it will break apart and that will be the end of everything." This thought is taken up by Sandy in Stardust Memories, who expresses his despair over the fact that " $[\mathrm{t}]$ he universe is gradually breaking down. There's not going to be anything left." In Hannah and Her Sisters (1986), another Allencharacter, Mickey Sachs, has a terrible moment in the film when the inevitability and irrevocability of death dawns upon him, and realizes that there is little, if any, room for the hope of individual redemption in the face of the brute factuality of physical annihilation. In September (1987), a physicist named Lloyd (Jack Warden) explains that even more horrifying than the destruction of the Earth by an atomic bomb is "the knowledge that it doesn't matter one way or the other," that the universe is "all random, radiating aimlessly out of nothing, and eventually vanishing forever."

The thought of "vanishing forever" is just as disconcerting to Allen himself as it is to his fictional characters, which he explains in a recent biographical documentary as follows:

$[S]$ omewhere around five or so, I turned grumpier, or sour. I can only think when I became aware of my mortality, I didn't like that idea. 'What do you mean, this ends? This...you know...this doesn't go on like this?' 'No, it ends. You know...you vanish. Forever.' Once I realized that, I thought, 'Hey, you know... deal me out. I don't want to play in this game.' And I never was the same after that ... I'm not saying my grim appraisal is right . .. but this was only my particular take on everything: that we all know the same truth, and our lives consist of how we choose to distort it.

What one can observe beyond the bleakness of Allen's blasé contentions is a certain demystifying intent. His brooding characters, besides the comic element, seem to have an air of prophetic heroism around them, as though they were blessed or cursed with the ability to cut through the comforting fictional constructs offered 
by their culture, and see "reality" in its most naked and cruel form. Notably, Allen refers to these comforting fictions in his biographical interview as "distortions," that is, falsifications of the "truth," whereby he leaves no doubt as to which side of this epistemological divide he finds more favorable. For him, confronting the inevitability of our demise (both individually and cosmically) yields an epistemically privileged truth, which rises above the socially constructed fictions (the distortions) which help to dissimulate that very truth.

While Allen's claim to fame is not that he has ever aspired to the status of a professional philosopher, his character-portrayals as well as his biographical recollections arguably show an affinity with specific philosophical themes, especially in existentialist thought. Viewed from the perspective of existentialist philosophy, his status as a "demystifier" can be legitimated less by his vindication of a privileged and authoritative meta-position, than a certain sense of anxiety (Angst) in a specifically Heideggerian sense. What one has Angst about, according to Heidegger, is "being-in-the-world as such" (precisely the predicament Sandy Bates's psychiatrist - using Heideggerian terminology in the film-attributes to his patient). This differentiates it from fear proper, in that fear is occasioned by some "innerwordly being" (174), which is irrelevant to Angst. Thus, the sense of threat generated by Angst "does not have the character of a definite detrimentality which concerns what is threatened with a definite regard to a particular factical potentiality for being. What Angst is about is completely indefinite" (174). The threat is nowhere and ultimately nothing, from which Heidegger concludes the following: "So if what Angst is about exposes nothing, that is, the world as such, this means that that about which Angst is anxious is being-in-the-world itself" (175; emphasis in original). At the same time, Angst does not merely denote the state of being anxious: it is also a mode of "attunement" (grasped by Heidegger in the dichotomy of "Angst about" vs. "Angst for"), which has the capacity to distance us from our ordinary roles and functions, which normally determine and delimit our perception of the world: "Angst as a mode of attunement first discloses the world as world . . . In Angst, the things at hand in the surrounding world sink away ... Thus, Angst takes away from Da-sein the possibility of understanding itself, falling prey, in terms of the 'world' and the public way of being interpreted" (175), which entails a sense of freedom, coupled with a sense of uncanniness ("not-being-athome" [176]). This gives rise to what Heidegger calls "existential solipsism," which constitutes an outsider position from which the world and existence reveals itself in its perverse absurdity.

Viewed from this Heideggerian perspective, neither the experience of one's own death, nor (and even less so) the cruel indifference of the universe qualifies as an "innerwordly" threat, while being-in-the-world inevitably entails all of those 
unfathomable threats about which Allen and his characters seem to be so anxious, even though most people may choose to ignore them. Allen's Angst manifests itself precisely in the manner in which he distances himself from ordinary ways of perceiving and dealing with individual and cosmic annihilation, assuming an outsider's position, whereby he does seem to wish to escape from "the public way of being interpreted." Moreover, the demystifying narratives with which he presents his viewers have a genuine sense of the uncanny about them: they compel us to confront truths that are painfully familiar, but at the same time they generate an uneasiness that has an alienating effect-it is certainly not easy to feel "at home" in Allen's demystifying discourse.

Besides the existentialist angle, which marks out Allen's position as an "outsider" rather than a self-appointed Platonist "philosopher king," in what follows I will concentrate on a perhaps less obvious philosophical relevance to his work, which is related to the cognitive aspect of his demystifying intentions. It is worth recalling Allen's statement in the interview that the eventual demise of the individual and the universe is a truth which "we all know," implying that being aware of the falsifications makes our voluntarily blindness all the more condemnable. On the other hand, a legitimate case can be made by arguing that what Allen calls "distortions" originate from the partly epistemological, partly moral (but in any case culturally determined) necessity to help explain and cope with the cruel truths of our existence. From this perspective, the demystification looks rather like a carefully crafted rhetorical trick than an act of revelation, which derives its efficacy precisely from the entrenched status of the comforting fictions. This view, in turn, also enables us to rise above the dichotomies of "fiction vs. truth," "faith vs. knowledge." "blindness vs. insight," etc., and interrogate the processes of knowledge production in a way which combines philosophical inquiry with a culture-based approach.

If we revisit the analyst's description of Sandy Bates's predicament, we will find Allen's argument for demystification presented in an ironically reversed form: "faulty denial mechanism failed to block out the terrible truths of existence," so he was unable to "push away the awful facts of being-in-the-world." Allen's irony depends for its efficacy on reversed psychology, for at first sight it runs counter to our rational faculties to regard denial as the norm and render clear-sight as a "faulty mechanism," which is the conclusion he seems to want us, viewers, to draw. Nevertheless, the reversal generates irony on its own terms, despite Allen's original intention, as there is a philosophically legitimate literal reading of the psychiatrist's description, if we take it to mean that social and cultural practices (including the comforting fictions of religion or the arts) serve not only to mediate our confrontation with the naturally given, but they are also capable of 
constituting our first-order reality. Even Richard Rorty, who has never ceased to debunk metaphysical thought, concedes that he "cannot imagine a culture which socialized its youth in such a way as to make them continually dubious about their own process of socialization" (87). In the same vein, one would be hard pressed to find a society in which the education of the young ones begins with teaching them about the ruthless indifference of the natural world, prior to introducing them to the tales, songs, myths, poems, historical narratives, or religious beliefs of their respective cultures (this is what makes the character of young Alvy Singer so irresistibly hilarious). Once one's initiation into such a cultural matrix has taken place, the "undistorted truth" can only emerge from within that matrix, but if that truth is found to be in conflict with the network of beliefs which constitute the matrix, it is likely to be dismissed as falsehood, fabrication, sophism, or at best "your truth against mine." A more complex case occurs if the dismissal does not happen out of hand, but rather through offering a counter-narrative (in some cases more, in some cases less elaborate) which aims to explain why, for instance, faith in eternal life is a more plausible, even rational (and not simply more comforting) position to hold than the awareness of irrevocable annihilation after death. The latter case is far more interesting than the former, as it implies that the one whose beliefs are being challenged with a demystifying intent finds the opponent's argument compelling enough to take the trouble to formulate a counter-argument so that they can continue to hold those beliefs. The phenomenon which results is widely known by the term "cognitive dissonance," which is by no means restricted to the relatively common debates between faith and reason, but it can occur at multiple levels of intellectual proficiency, even among the scientifically or philosophically well-trained (Smith 5).

The theory of cognitive dissonance was put forward in 1957 by American social psychologist Leon Festinger, based on the observation from previous experiments that "persons are not always successful in explaining away or rationalizing inconsistencies to themselves . . . Under such circumstances- that is, in the presence of an inconsistency-there is psychological discomfort" (Festinger 2). Replacing the term "inconsistency" with "dissonance" (because, as he put it, it has "less of a logical connotation"), he proposed the first basic hypothesis of his theory as follows: "The existence of dissonance, being psychologically uncomfortable, will motivate the person to try to reduce the dissonance and achieve consonance"3 (3). The scope of the theory's applicability, expounded by Festinger in his $A$ Theory

3 The second one of his two basic hypotheses, which is less relevant to our discussion, states: "When dissonance is present, in addition to trying to reduce it, the person will actively avoid situations and information which would likely increase the dissonance" (Festinger 3). 
of Cognitive Dissonance, is less relevant to a philosophically ingrained discussion than the research which lay the groundwork for its formulation, and especially the way in which Festinger and his group interpreted the findings. Festinger and his collaborators, ${ }^{4}$ infiltrated a doomsday cult, which predicted a global cataclysm to take place on December 21 1954. Festinger and his research group were interested to find out how the behavior of the cult members would change in the wake of the inevitable realization that the apocalypse did not happen on the appointed day. The scientists paid special attention to how the cultists managed to explain away the failure of the prophecy in such a way that they could continue to hold on to their beliefs (Smith 2-4). It is easy to understand how the theory of cognitive dissonance followed logically from this particular research, but it is all the more surprising how the scientists' interpretation revealed their own proclivity for explaining away the dissonance that they encountered. As Barbara Herrnstein Smith explicates, the research group operated with the hypothesis that the cultists' faith would not be disconfirmed by the failure of the prophecy, and that the explanations they formulate for the failure would continue to foster group cohesion among them. The result, however, turned out to be more varied than it was expected: several members left the cult and only a few of them would continue to spread the word to recruit new members (Smith 4). The surprising element is the following: "Like their subjects ... the scientists exhibited considerable resourcefulness in explaining the relevant disparities of expectation and experience-in the scientists' case, largely by discounting recalcitrant portions of the data as 'unclear' and, in the formal conclusion of the report, describing and interpreting events in ways that minimized their difference from what had been predicted" (Smith 4). This leads Smith to conclude that the tendency to retain one's prior beliefs in the face of disconfirmation is not "altogether eradicated by scientific training or good-faith efforts at objectivity ... [;] once we have framed an explanation of some puzzling phenomenon, we are strongly inclined to be most alert to what confirms it" (5).

While in the case of scientists, the cognitive dissonance and the attempts at explaining it away can be discerned through examining the hypothesis, the data, and their interpretation, it is more difficult to find such points of reference in the case of critical commentaries on works of art, including (and perhaps especially) literary and filmic texts. Critical interpreters also operate with hypotheses of some sort, but what qualifies as interpretable "data" in a text or a film remains dubious, nor is there any formal consensus about methods of literary or filmic interpretation. Moreover, we, literary critics and theorists, pride ourselves on the

4 Henry Riecken and Stanley Schachter, with whom he published their findings in a book titled When Prophecy Fails in 1956. 
diversity and inclusiveness of our discipline: following in the footsteps of the narrator of Henry James's famous story, we are looking to discover figures in the carpet, but the figures we claim to see remain functions of the hypothesis which informs the reading. Literary and filmic texts rarely present falsifiable claims or refutable arguments, and for this reason, distinguishable occurrences of cognitive dissonance are so minimal that one might tend to believe they are nonexistent in literary or filmic criticism.

Even though such occurrences might be rare, they are all the more intriguing to explore when they are found to arise. In the following, I will concentrate on two philosophically conceived critical interpretations of Allen's Crimes and Misdemeanors, which perform highly erudite readings of the film, but its pessimistic moral outlook generates an urge in the commentators to find a sophisticated philosophical apologia to explain away the inconvenience of the filmic narrative. The result is a remarkable case of the emergence of cognitive dissonance in an otherwise perspicuous and rational philosophical discourse.

\section{Crimes and Misdemeanors: the worst nightmare of moral philosophers}

Crimes and Misdemeanors (henceforth Crimes) runs two parallel storylines: one follows Dr. Judah Rosenthal (Martin Landau), a successful ophthalmologist, the other, Cliff Stern (Woody Allen), a less than successful independent filmmaker. Judah is a well-respected and wealthy medical doctor, a family man, which does not stop him from starting a relationship with a younger woman, Dolores Paley (Anjelica Houston). One day, Dolores confronts the doctor with the request that he should leave his wife and marry her. She would not shy away from divulging everything to the wife or even blackmailing Judah, threatening him to go public with the information that the doctor embezzled from the foundation of which he was put in charge. Desperate to keep his reputation intact, he resorts to calling the black sheep of the family, his brother, Jack (Jerry Orbach), who apparently is no stranger to the world of organized crime. Jack offers to have Dolores' killed, which Judah initially refuses, but when fear for his reputation and his cocooned family life gains the upper hand over conscience and conventional morality, he eventually decides to make the deadly phone call. Dolores gets killed by a hitman, whereupon Judah initially finds himself torn up by guilt, feeling that his whole world is falling apart as he constantly frets legal and even divine retribution. Finally, however, the police catch a "drifter," a multiple murderer, on whom the murder of Dolores can be conveniently blamed, so Judah can finally retreat to his former life of "wealth and privilege," with bad conscience no longer troubling him. 
Meanwhile, Cliff's life is in shambles: he receives no recognition for his socially and environmentally conscious documentaries on poverty, famine, or acid rain, and even his marriage is deteriorating. His wife's brother, Lester (Alan Alda), a wealthy and successful television producer, as a gesture to his sister, offers Cliff the opportunity to shoot a documentary on him for the Great Minds series. Cliff reluctantly accepts, hoping to channel the money he would earn on it into his more worthy projects, such as the documentary he is preparing on philosophy professor Louis Levy (Martin Bergmann). He can only find comfort in attending matinee screenings of old Hollywood classics with his niece and a budding love affair with Halley, an assistant producer on the series (Mia Farrow). Eventually, things turn out badly for Cliff: Professor Levy commits suicide, he loses Halley to Lester, and his marriage breaks off for good. To add insult to injury, Lester fires him due to the fact that Cliff's tampered editing of the raw film footage for the documentary shows Lester as a self-centered, manipulative, and pretentious brat. The final words of the film are given to the late Professor Levy in a voice-over narration, in which he acknowledges that "human happiness does not seem to have been included in the design of creation," but our "capacity to love" may give meaning to the "indifferent universe," and he expresses hope that "future generations might understand more." However, his consoling words come far too late to redeem the pessimism of the film: by this point, Dolores is dead, Judah, Jerry, and the hitman have gone unpunished, and the professor himself has committed suicide. ${ }^{5}$

It is hardly surprising that commentators have found themselves confounded by the bleak vision of the film, which leaves no hope of redemption for the grumpy and hapless, but honest and good natured Cliff, while showing an adulterer, embezzler, and virtual murderer, Judah, go unpunished, and the pompous and phony Lester gratified in love and continuing to prosper in his professional life. Two critics, who have offered philosophically ingrained readings of Crimes, John G. Pappas and James Lawler, are both acutely aware of the radical skepticism of the film, yet they seem to be unable to repress the urge to counterbalance the apparent despondency of the narrative by appealing to universalist notions of morality, which might still shine through the schemings of the Judahs and the self-important posturings of the Lesters.

Pappas uses the story of the ring of Gyges from Plato's Republic to perform a thought experiment along Socratic lines, asking the question: how would the three

5 Sander H. Lee interprets Professor Levy's unexplained suicide as a corollary to his philosophical convictions. He contends as follows: "Louis Levy finally realized . . . the ultimate extension of Hannah Arendt's famous description of "the banality of evil," and, being a fundamentally honest person, concluded both that nothing he could say or do would stop this degradation, and, further, that he no longer wished to live in such a world" (259). 
male characters (Lester, Cliff, and Judah) behave, if the power of Gyges' ring of invisibility were conferred upon them? While it is arguably hard to settle on the Socratic conclusion that "virtue is its own reward," as probably none of us would swap places with the ill-fated Cliff, Pappas argues that from among the three men, it is Cliff who is the least likely to use the ring for his own selfish or evil purposes:

[W] ought to believe that Clifford, bequeathed the wealth and power that Lester possesses, would use his "ring" in a decent, fair, and honest manner. Again, evidence of Clifford's good-nature is that, handed the vast power to further craft Lester's phony image to demi-god status and simultaneously garner wealth and prestige for himself, Clifford actually exposes the truth about Lester, [even at the expense of getting fired]. (212)

Furthermore, he goes on to conclude that

[a]s we reflect on the film's pessimism, our thoughts and feelings are curiously provoked and heightened. They are a mixture of the wonders and paradoxes of our own human nature and existence. Plato's Gyges story in his Republic and Allen's Crimes and Misdemeanors encourage us in our lives to continue a search for justice and moral enlightenment. In this wonderful mysterious, examined life, then, maybe we could hesitatingly claim, "It's not all darkness." (217)

Although Pappas does not justify his position by outright metaphysical arguments, his reflections markedly aim at neutralizing the disenchanted moral outlook of the film, whereby the sharp contrast between his interpretation and the argument of the film gets all the more thrown into relief. Why should it be Cliff who turned the power of the ring for morally worthy causes? Most probably because he is the least obnoxious of the three characters, and he is the ultimate loser of the story, who thus earns our sympathy. But is this a sufficient test of his overall moral stature? After all, why would it be any less plausible to interpret Cliff's (mis)representation of Lester in his documentary as stemming from petty jealousy and spite than to assume that he was operating with the morally commendable purpose of "exposing the truth" about his brother-in-law? While Lester's character might be closer to Cliff's eventual representation of him than what he would have expected to see in a flattering portrayal, we must not forget that the "truth" which emerges in Cliffs film is expressed through a concoction of manipulatively edited film footage, which includes inserts of Mussolini and a hee-hawing donkey to highlight and ridicule certain personality traits of Lester (as perceived by Cliff). 
In fact, Cliff is not only the least obnoxious, but also the most powerless of the three men, so his moral standing has never been compromised by the temptations of money and fame. Judah is tried and he fails, but he is never found wanting: his wealth and social status protect him against retribution, and he eventually revels in his newly found freedom without a modicum of remorse. Judah's getting away with murder must be morally scandalizing for any decent viewer, which makes it all the more difficult to allow for the insight that his moral failure does not originate from innately evil inclinations, but is rather an upshot of a contingent factor: social privilege. The "drifter," on the other hand, is described by Judah as a person "who has a number of other murders to his credit, so I mean..., what the hell, one more doesn't even matter." Thus, the scapegoated drifter's fate becomes the perfect counterpoint to that of Judah: although the doctor's professional expertise, his wealth, and his success all enhance his "social visibility," the very same factors make law-enforcement authorities and legal institutions blind to his crime; by contrast, the drifter's underprivileged status makes him socially invisible, yet, coupled with his criminal record, his "invisibility" turns him into a convenient excuse for improving the police statistics of solved crime cases even at the expense of trivializing justice as well as Dolores's murder.

These are rather harrowing facts, which can justifiably undermine one's faith in universally valid moral principles and justice. Pappas seems none the less affected by this blatant pessimism, so in his commentary he seems to attempt to restore some of the metaphysical comforts the film so cruelly denies us, thus reducing the dissonance that the film generates. This is apparent in his contention that the film should serve as an incentive for the viewers to affirm their faith in "justice" and "moral enlightenment," but he does not provide any clues as to what could serve as a rational foundation for such an affirmation after a thoroughgoing deconstruction of "justice" and "morality" as stand-alone categories. Allen's demystifying narrative is far more convincing than to explain it away by the same mystifications which it seeks to dismantle. The most positively inclined approach could be to regard the film as a defamiliarization of our entrenched and unexamined convictions, arguing that justice and morality are not found as natural kinds, but neither are they exactly constructed in an arbitrary fashion. Rather, they ideally result from an optimal functioning of social practices, where the criteria for ideality will have been agreed upon before we, as individuals, enter the realms of social and cultural discourse. We are well aware of those criteria, which is the reason why we gasp at the abominable injustice of the wrongdoer getting off the hook contrasted with Cliffs professional, financial, and marital failure, and his righteous rabbi brotherin-law, Ben, going totally blind at the end of the film. Feeling outraged over such an unfair unfolding of events may seem like a passive reaction, but it might well 
be our best bet against injustice and immorality, as it indicates an awareness of the social and institutional norms which render such injustice condemnable. Nonetheless, hoping to ground our outrage in something more fundamental than social practice requires a narrative that is more convincing than Allen's bleak, but undoubtedly rational and economical account of the socially constructed nature of morality.

James Lawler hopes to find this narrative in the moral philosophy of Immanuel Kant, which results in a philosophically more reflexive argument than that of Pappas, but he also goes further along the lines of metaphysical thinking. Lawler offers a professedly Kantian analysis of the film, which seems rather controversial in the context of a work which could not be further from Kantian philosophy in outlook. As a consequence, the thoroughgoing and sensitive argument perforce maneuvers itself into a self-defeating extolment of subjectivity, which does not do justice either to Kant's philosophy, or to Allen's film. Laying down the premises of his analysis, Lawler claims to paraphrase Kant's argument from Critique of Pure Reason, according to which "the so-called real world, the universe as portrayed by science as a morally indifferent place, is not so real after all" (Lawler 41), and goes on as follows:

It [the real word] is only an "appearance," built up in part out of the underlying structures of the mind that we employ when we seek to organize knowledge. When we pursue scientific knowledge, we inevitably employ categories of strict causality. But these categories reflect the structure of the human understanding and its "transcendental logic," not the nature of reality as it is in itself. [Thus] ... the "logical" categories of a deterministic science are in fact subjective, not objective. They express the way in which human beings, in their scientific enterprise, subjectively organize experience, not the nature of reality itself. Beyond the "logic" of a mechanistic science is a more fundamental truth, expressed in religious traditions, in the aspirations of the human heart, and in the implicit assumptions of moral consciousness. This is the truth that the universe in fact has meaning and purpose- that of fostering the Highest Good. (41-42)

The passage is more reflexive of Lawler's own views than Kant's original reasoning. The point being made is analogous to my contention above, according to which the cultural practices into which we are born, and the cultural narratives which they generate will always already serve as a buffer between "pure reality" and human perception (hence, "pure reality" is a useless term). Thus far Lawler's reasoning is correct, but when he proceeds to interpret the actions and motivations of the film's 
characters in terms of how they measure up to the Kantian ideal of deontology, he seems to start operating with articles of faith rather than rational insights. $\mathrm{He}$ invokes Kant's notion of authentic freedom, according to which there is no higher power than that of the Moral Law, which determines the will and actions of the individual, over which those who possess mere political or institutional power will not hold sway. Once the individual recognizes where the path of moral action lies even in the face of life-threatening forces pressuring him/her to the contrary, s/he will perform what is right even at the cost of self-denial. Thus, Lawler contends, when "Judah has to choose between his own life and killing an innocent person . .. he should have the experience of authentic freedom. And yet Judah is intent on denying just such a possibility. He rationalizes and denies" (44; emphasis added). Furthermore, commenting on the imaginary conversation between Judah and Ben right before the former decides to have Dolores killed, Lawler claims that "[a]s in Kant's moral imperative, God sees the intrinsic dignity of Dolores. Judah should see that too — see with God's eyes of love" (44; emphasis added). Instead, he goes on to say, "Judah locks himself into one view of the world, that of 'reality,' the worse than dog-eat-dog, indifferent, loveless world of egoism and survival. But this 'real world' that Judah chooses is in fact an appearance, as Kant says, and as the characters of the film themselves acknowledge" (44-45).

From this, the following question arises inevitably: is there any logical method whereby it could be qualitatively demonstrated that the ideally hypothesized world in which the Moral Law prevails is any less of an appearance than the "indifferent, loveless world of egoism and survival"? In the longer passage quoted above, Lawler associates this latter world with the "logical categories of deterministic science," and claims that scientific attempts at objectivity (apparently the token of emotionless indifference for Lawler) can only produce subjective appearances. He provides no rational argument, however, for his claim that religion, emotion, and moral consciousness constitute a "more fundamental truth" than logic and science. Does "more fundamental" mean "more objective"? If so, what makes our capacity to organize experience better suited to produce objective knowledge than it does in scientific discourses? On the other hand, if, from Lawler's perspective, neither discourse can be regarded as more objective than the other, the preference for one over the other becomes a matter of faith, and as such it dispenses with all criteria of falsifiability. One could rationally argue that because an individual's socialization in emotive and moral terms (potentially including religious teachings) most likely precedes their initiation into science and logic, their understanding of scientific discourse can be positively or negatively affected by their emotional and moral knowledge. Nevertheless, the sheer fact of antecedence does not invalidate scientific knowledge in the face of moral convictions. 
Once we give up the naïve belief that the function of science is to help us catch glimpse of the ultimate reality of the world as it is, we can acquire a more nuanced view according to which the aim of science is to provide us with an ever expanding body of knowledge, which helps us cope with the world. This knowledge, however, is not arbitrary or subjective, as it is under constant social surveillance in the sense that it is discussed, debated, tested, interpreted, verified, and altered, if needs be, in/by scientific communities. Empirical methods of inquiry are fundamental to any scientific endeavor, but even scientists cannot dispense with discursive practices in assessing and applying their findings. Furthermore, coherence among knowledge claims can be achieved by first reaching consensus over optimal ways of coping and goals to be achieved. By the same token, there is no reason to suppose that moral knowledge is any less dependent on social and discursive practices than scientific knowledge, and that it gets constructed, sustained, and altered any differently. To claim that moral knowledge is informed by "a more fundamental truth," that of the "universe" having "meaning and purpose" is a rather specious metaphysical, hence unprovable, claim, and it does not quite do justice to Kant, either.

The guiding principle of Kant's deontological moral philosophy is that ethics must be divorced from all forms of empirical (hence, by implication, social, cultural, political, institutional, etc.) considerations, from conditions, consequences, and utility. Therefore, passions and desires, the anticipation of pleasure or pain, or any kind of momentary self-interest must not play a role in determining the agent's will towards moral action, and any moral rule arising from these can at best be a "maxim," not a law. Kant's formulation of the fundamental law of "the pure practical reason" is the following: "Act so that the maxim of thy will can always at the same time hold good as a principle of universal legislation" (Kant 119). Moral laws (categorical imperatives) are a priori, intrinsically valid, and unconditional, originating from pure practical reason, which Kant painstakingly endeavors to isolate from any extrinsic factor which could contaminate its purity. As he contends: "[b]ut that reason may give laws it is necessary that it should only need to presuppose itself, because rules are objectively and universally valid only when they hold without any contingent subjective conditions, which distinguish one rational being from another" (Kant 107). As a corollary to this:

Laws must be sufficient to determine the will as will, even before I ask whether I have power sufficient for a desired effect, or the means necessary to produce it; hence they are categorical: otherwise they are not laws at all, because the necessity is wanting, which, if it is to be practical, must be independent of conditions which are pathological and are therefore only contingently connected with the will. (Kant 106) 
For this independence to be achieved, such a level of abstraction is required at which the moral law is in effect reduced to its mere form:

Now, when we abstract from a law all matter, i.e., every object of the will (as a determining principle), nothing is left but the mere form of a universal legislation. Therefore, either a rational being cannot conceive his subjective practical principles, that is, his maxims, as being at the same time universal laws, or he must suppose that their mere form, by which they are fitted for universal legislation, is alone what makes them practical laws. (Kant 11415)

Lawler seems to overlook Kant's key concepts of universality, unconditionality, and purity in his (allegedly Kantian) analysis of Crimes, whereby he turns Kantian moral philosophy into the exact opposite of what it purports to be: a repository of truistic maxims. In fact, nothing reveals this tendency better than his repeated use of the modal "should": the prescriptive claim for Judah to experience authentic freedom upon contemplating murder, and see Dolores' dignity through "God's eyes of love" (a notion never mentioned by Kant) is highly ironic, considering how Judah dismisses all moral principles of universal appeal and acts solely with regard to his own self-preservation.

It is Ben to whom Judah turns for advice in his predicament, but when the rabbi testifies to his own moral faith, saying, "I couldn't go on living if I didn't feel with all my heart a moral structure with real meaning and forgiveness, and some kind of higher power, otherwise there is no basis to know how to live," Judah remains conspicuously impervious to this proposition. Ben makes an attempt to persuade the doctor to confess his infidelity to his wife, Miriam, but he can do no more than appeal to a general principle, suggestive of the rhetoric of religious sermons: "Sometimes when there is real love, and a true acknowledgement of a mistake, there can be a forgiveness, too." Not surprisingly, Ben's advice is lost on Judah, who is quick to expose the vacuity of this benevolent, but bland wisdom by transposing it to the specific context of their marriage, saying: "I know Miriam, her values, her feelings, our place among our friends and colleagues ... Miriam won't see two years of scheming and dishonesty as a small infidelity."

Judah's moral outlook could not be further removed from the Kantian ideal: giving in to the passions of momentary pleasure, he commits adultery, and hides the fact from his wife so as to avoid the pain of public humiliation for his family and himself, which eventually makes him decide to hire a hitman to take care of his "problem." Thus, the anatomy of Judah's misdemeanor (adultery) and crime (murder) is composed of small, contingent factors, forming a causal pattern, which 
eventually lead to the murder of a woman. At each instance of decision-making, Judah acts in accordance with what he thinks is "right," but "rightness" in this regard is defined by how much pleasure or pain he is to expect from one course of action as opposed to another. None of the maxims Judah might deploy to defend his actions would he (or anyone else in his place) even think of elevating to the level of "universal legislation." Indeed, any thought of universality, unconditionality, or purity is precluded right from the start.

The purpose of my analysis above has not been to prove that Pappas and Lawler have insufficient knowledge of the philosophy they apply to Crimes, nor even to demonstrate that their interpretations are wrong. On the contrary, both critics appear to be well-versed scholars in full command of their philosophical forces. It is precisely their philosophical erudition that makes their endeavor to churn a hopeful philosophical message out of the film so conspicuous. The dissonance which occurs seems to be generated by their philosophical convictions about the universalist foundations of morality, and their refusal to accept the film's argument at face value, retaining the belief that a fictional narrative (a "work of art") is a symbolic discourse, whose basic mode of operation is aestheticization and sublimation. The comforting fictions do indeed prove to be powerful constructions, even in the realm of philosophical discourse.

\section{Concluding notes, or, can we save the author from his own pessimism?}

Ironically, in the final scene of Crimes, it is Allen's own character, Cliff, who is given the lines to mitigate the grim conclusions we can draw from Judah's sordid story. Upon their accidental encounter, disguising it as an idea for a movie script, Judah relates his "great murder story" to Cliff, which, he says, "has a very strange twist," referring to the murderer finally getting away with his crime: "Now he's scot-free [after the drifter is arrested]," Judah concludes his story, "his life is completely back to normal. Back to his protected world of wealth and privilege." Cliff, however, responds in a skeptical manner: "Yes, but can he ever really go back? ... [Because if it is possible], then our worst fears are realized ... Here's what I would do: I would have him turn himself in, 'cause then you see... then your story assumes tragic proportions, because in the absence of a god or something, he is forced to assume that responsibility himself. Then, you have tragedy." To this, Judah responds, followed by a derisive chuckle: "But that's fiction, that's movies. I mean... you see too many movies. I'm talking about reality. I mean if you want a happy ending, you should go see a Hollywood movie."

Judah's meta-reflexive remark could justifiably be ascribed to Allen himself, as though sending a warning to future critics of the film: although the medium 
might be deceptive, this is not your run-of-the-mill movie, in which the story comes with a conventional morale, so do not even try to read one into it. In fact, though they seem to represent different perspectives at first, eventually both Judah and Cliff confirm the intuition that the ethos of moral justice is a property of fictional constructs. Judah's father, Sol, also affirms this insight in a flashback of a Seder night where a heated debate breaks out over moral convictions between the religious and atheistic members of the family: "Whether it's the Old Testament or Shakespeare, murder will out"-Sol proclaims. Indeed, fictions of various kinds play a significant role in our moral education, which is the reason why we feel confounded and inconvenienced by fictional stories which outright tell us that what we knew about morality and ethics is itself fiction.

I conclude my paper with a final example of a commentator's attempt to reduce the cognitive dissonance generated by Crimes, even (and literally) in the face of the auteur. Sander H. Lee in his reading of the film, having analyzed the narrative almost scene by scene, and having given due account of Allen's moral pessimism, turns his interpretation around in the final section (aptly titled, "And Yet..."), and claims that Judah's return to his protected life is just a charade: "it is more likely that his high spirits at the film's end are temporary, and that, in the long run, he will secretly torment himself for the rest of his life" (270). More interestingly, Lee presents his redemptive interpretation to Allen himself in an interview, which the director unambiguously rejects: "You are wrong about Judah;" he tells Lee, "he feels no guilt and the extremely rare time the events occur to him, his mild uneasiness (which sometimes doesn't come at all) is negligible" (Lee 271). Lee, however, remains unconvinced: "I would [still] argue that the film's text gives stronger support to my interpretation ... . [For] I would contend that in many instances artists do not possess privileged access to all of the nuances of their creations" (271). In a general sense, Lee could be right: the profession of literary criticism has long since operated with a license to discover figures in the carpet, setting aside the author's intentions (in the rare cases in which they have been made available at all). Nevertheless, the motif of Judah's self-exoneration is not just a figure in the carpet, but rather the very material out of which the carpet has been woven. Moreover, it constitutes a strong premise to the stern but unequivocally stated argument that one's sense of guilt and troubled conscience can merely be fear of being found out and punished; once retribution has been avoided, the guilt evaporates. In fact, the strength of the argument is indicated precisely by the fervent attempts of the commentators to reduce it. Furthermore, considering the frequency with which Allen addresses the inconvenient truths of our existence in several films of his middle period, a strong case can be made for the claim that his artistic vision is conjoined by a consistent conceptual outlook. This could well be 
a case in which the author does not need saving from the putatively unwanted implications of his work. Therefore, Allen's Crimes and Misdemeanors offers an exceptional perspective to explore cognitive dissonance in the discourse of literary/ filmic criticism, in which such anomalies are normally dissolved, and hence remain concealed.

\section{WORKS CITED}

Conard, Mark and Aeon Skoble eds. Woody Allen and Philosophy: You Mean My Whole Fallacy Is Wrong? Carus, 2004.

Festinger, Leon. The Theory of Cognitive Dissonance. Stanford UP, 1957.

Heidegger, Martin. Being and Time (1953). Trans. Joan Stambaugh. SUNY Press, 1996.

Kant, Immanuel. The Critique of Practical Reason. Trans. Thomas Kingsmill Abbott. London: Longmans, 1889.

Lawler, James. "Does Morality Have to Be Blind? A Kantian Analysis of Crimes and Misdemeanors." Conard 33-47.

Lee, Sander H. Eighteen Woody Allen Films Analyzed: Anguish, God, and Existentialism. McFarland \& Company, 2002.

Pappas, John G. "It's All Darkness: Plato, the Ring of Gyges, and Crimes and Misdemeanors." Conard 203-17.

Rorty, Richard. Contingency, Irony, and Solidarity. Cambridge UP, 1989.

Smith, Barbara Herrnstein. Natural Reflections: Human Cognition at the Nexus of Science and Religion. Yale UP, 2009.

Annie Hall. Dir. Woody Allen. Perf. Woody Allen, Diane Keaton, and Tony Roberts. United Artists. 1977. Film

Crimes and Misdemeanors. Dir. Woody Allen. Perf. Woody Allen, Martin Landau, Mia Farrow, Alan Alda. Orion Pictures. 1989. Film.

Hannah and Her Sisters. Dir. Woody Allen. Perf. Mia Farrow, Dianne West, and Michael Caine. Orion Pictures. 1986. Film.

September. Dir. Woody Allen. Perf. Elaine Stritch, Denholm Eliott, and Mia Farrow. Orion Pictures. 1987. Film. 
Stardust Memories. Dir. Woody Allen. Perf. Woody Allen, Charlotte Rampling, and Jessica Parker. United Artists. 1980. Film

Woody Allen: A Documentary. Dir. Robert B. Weide. Perf. Woody Allen, Letty Aronoson, and Marshall Brickman. Whyaduck Productions. 2012. TV. 